Article

\title{
Immobilized Burkholderia cepacia Lipase on pH-Responsive Pullulan Derivatives with Improved Enantioselectivity in Chiral Resolution
}

\author{
$\mathrm{Li} \mathrm{Xu}^{\dagger}$, Guli Cui ${ }^{\dagger}$, Caixia Ke, Yanli Fan and Yunjun Yan* \\ Key Laboratory of Molecular Biophysics, the Ministry of Education, College of Life Science and Technology, \\ Huazhong University of Science and Technology, Wuhan 430074, China; xuli@hust.edu.cn (L.X.); \\ gulicui@hust.edu.cn (G.C.); kecaixia@hust.edu.cn (C.K.); D201577434@hust.edu.cn (Y.F.) \\ * Correspondence: yanyunjun@mail.hust.edu.cn; Tel.: +86-27-8779-2213 \\ † These authors contributed equally to this work.
}

Received: 12 December 2017; Accepted: 5 January 2018; Published: 9 January 2018

\begin{abstract}
A kind of $\mathrm{pH}$-responsive particle was synthesized using modified pullulan polysaccharide. The synthesized particle possessed a series of merits, such as good dispersity, chemical stability and variability of particle size, making it a suitable carrier for enzyme immobilization. Then, Burkholderia cepacia lipase (BCL), a promising biocatalyst in transesterification reaction, was immobilized on the synthesized particle. The highest catalytic activity and immobilization efficiency were achieved at $\mathrm{pH} 6.5$ because the particle size was obviously enlarged and correspondingly the adsorption surface for BCL was significantly increased. The immobilization enzyme loading was further optimized, and the derivative lipase was applied in chiral resolution. Under the optimal reaction conditions, the immobilized BCL showed a very good performance and significantly shortened the reaction equilibrium time from $30 \mathrm{~h}$ of the free lipase to $2 \mathrm{~h}$ with a conversion rate of $50.0 \%$ and $e e_{s}$ at $99.2 \%$. The immobilized lipase also exhibited good operational stability; after being used for 10 cycles, it still retained over $80 \%$ of its original activity. Moreover, it could keep more than $80 \%$ activity after storage for 20 days at room temperature in a dry environment. In addition, to learn the potential mechanism, the morphology of the particles and the immobilized lipase were both characterized with a scanning electron microscope and confocal laser scanning microscopy. It was found that the enlarged spherical surface of the particle in low $\mathrm{pH}$ values probably led to high immobilized efficiency, resulting in the improvement of enantioselectivity activity in chiral resolution.
\end{abstract}

Keywords: immobilization; Burkholderia cepacia lipase; chiral resolution; 1-phenylethanol; pullulan

\section{Introduction}

Lipases (triacylglycerol acylhydrolases, EC 3.1.1.3) are a class of promising biocatalysts owing to their catalytic diversity such as hydrolysis, esterification and transesterification [1,2]. Among them, Burkholderia cepacia lipase (BCL) is a versatile one and has been widely used in organic synthesis, biodiesel preparation, biodegradation and many other reactions in aqueous and non-aqueous phases [3-5]. Recently, enzymatic chiral resolution by lipases has generated huge interest due to the merits of it having fewer byproducts, a simple operation and environmental friendliness [6,7]. However, the freeform lipases generally exhibit low stability, poor recyclability and non-reusability $[3,8]$, especially low enzyme activity in non-aqueous phase reaction. These demerits were also reflected in the freeform BCL in our previous studies [3,9]. As we know, to employ a proper immobilization method can effectively improve enzyme activity and its dispersibility in solutions. For example, Lee et al. reported that sol-gel immobilized Candida rugosa lipase exhibited 10 times higher activity in esterification reaction [10]. So far, a number of materials have been used as immobilization carriers, 
such as insoluble gel, macroporous resin, carbon nanotubes, and so on. The basic principle is that the physical and chemical properties of the support materials should be stable and harmless to the enzyme. Generally, materials with good dispersibility, hydrophobicity and large surface area are the ideal ones for lipase immobilization [11,12].

Pullulan is a polysaccharide produced by the fungus Aureobasidium pullulans. It mainly consists of $\alpha$-(1-6)-linked maltotriose repeating unit and is easily commercially available [13]. Owing to the advantages of high water solubility, film forming, plasticity and easy biodegradation, pullulan has been widely applied in food and pharmaceutical industries [14]. There is much research on anti-cancer drug delivery using modified pullulan as drug carrier. Many pullulan derivatives have been synthesized for drug delivery systems such as $\mathrm{pH} /$ thermo-responsive pullulan-grafted copolymers [15], pullulan nanogel [16] and pullulan-doxorubicin conjugates [17]. It can be inferred that pullulan derivatives are safe, uniformly dispersed and chemically stable, making it a promising immobilization carrier. Furthermore, the $\mathrm{pH}$-responsive pullulan derivatives can significantly increase the immobilization efficiency and the immobilized enzymes can keep relatively high activity owing to the "pH memory" mechanism [18], even under the conditions that they are converted from the aqueous phase into the organic phase. However, since the patent "Enzyme Immobilized with Pullulan Gel" was published in 1981 [19], there have been few reports about the application of pullulan derivatives in enzyme immobilization. Thus, it is necessary and worthy to further explore such kinds of carrier, especially to focus on its sensitivity to $\mathrm{pH}$ value.

Moreover, 1-phenylethanol has been utilized in toiletries, chemical industries and many other fields as essential intermediate block. There is much research reporting enzymatic chiral resolution of $(R, S)-1$-phenylethanol and the catalytic efficiency can be easily compared between different enzymes [20]. Thus, chiral resolution of $(R, S)-1$-phenylethanol has been regarded as one of the model resolution reactions. The enantioselectivity $\left(e e_{s}\right)$, conversion and the duration to achieve reaction equilibrium are the principal factors in evaluating catalytic efficiency. For example, Chen et al. used Yarrowia lipolytica lipase to resolve $(R, S)-1$-phenylethanol via solvent engineering, increasing the $e e_{S}$ from $66 \%$ to $99.1 \%$ in pure n-hexane [21]. In addition, Antonia et al. obtained good conversion rates and high enantioselectivities $(92 \%->99 \%)$ of Candida antarctica lipase B using the essentially anhydrous protic ionic liquids in 2012 [22].

Therefore, $(R, S)$-1-phenylethanol chiral resolution reaction was utilized to assess the enzyme activity and catalytic efficiency of the freeform and the immobilized lipases. This study attempts to investigate a strategy for BCL immobilization using pullulan derivatives as carrier, to optimize the main affecting parameters on the immobilization efficiency and resolution ability during lipase immobilization, and to further discuss the probable mechanism for $\mathrm{pH}$ sensitivity of the immobilized enzyme. Thus, in this study, we aimed to develop a kind of immobilized lipase with controllable particle size by changing the $\mathrm{pH}$ value of the solution, which could benefit future application of the immobilized lipase or the combination with other immobilization strategies.

\section{Results and Discussion}

\subsection{Particle Characterization and $p H$ Responsibility}

The morphology of the synthesized carrier is shown in Figure 1. The modified pullulan polysaccharide was turned into spherical particles through diafiltration, achieving a good dispersion in reaction mixture. In the view of high magnification, the spherical particles were not a typical smooth sphere but a rough surface. This structure led to a larger specific surface area at $4.57 \mathrm{~m}^{2} \cdot \mathrm{g}^{-1}$ measured by BET method in $\mathrm{N}_{2}$ adsorption, which would contribute to higher immobilization efficiency.

As shown in Figure 2, the average particle sizes in different $\mathrm{pH}$ values were measured via DLS analysis, indicating the synthesized carriers had very good $\mathrm{pH}$ sensitivity. When the solution $\mathrm{pH}$ decreased from 10.0 to 4.0 , particle sizes were gradually increased, especially within $\mathrm{pH}$ values from 7.5 to 6.0 , the particle sizes were sharply increased. This phenomenon was mainly due to the 
introduction of sulfadimethoxine (SDM), a member of the sulfonamide family, which is an important factor responsible for the polymer $\mathrm{pH}$ sensitivity [23]. In an acidic environment, SDM was deionized and became hydrophobic, which led to a strong self-assembling of the pullulan derivatives. On the contrary, in the alkaline environment the ionized SDM was hydrophilic, so the pullulan derivatives were rather evenly dispersed than assembled. Therefore, larger particle size was obtained at lower $\mathrm{pH}$ while smaller size at higher $\mathrm{pH}$ as shown in Figure 2. Moreover, lipase immobilization was achieved within the self-assembling of the synthesized carriers, a larger particle size would lead to a higher immobilization efficiency owing to the occurrence of embedding and adsorption.

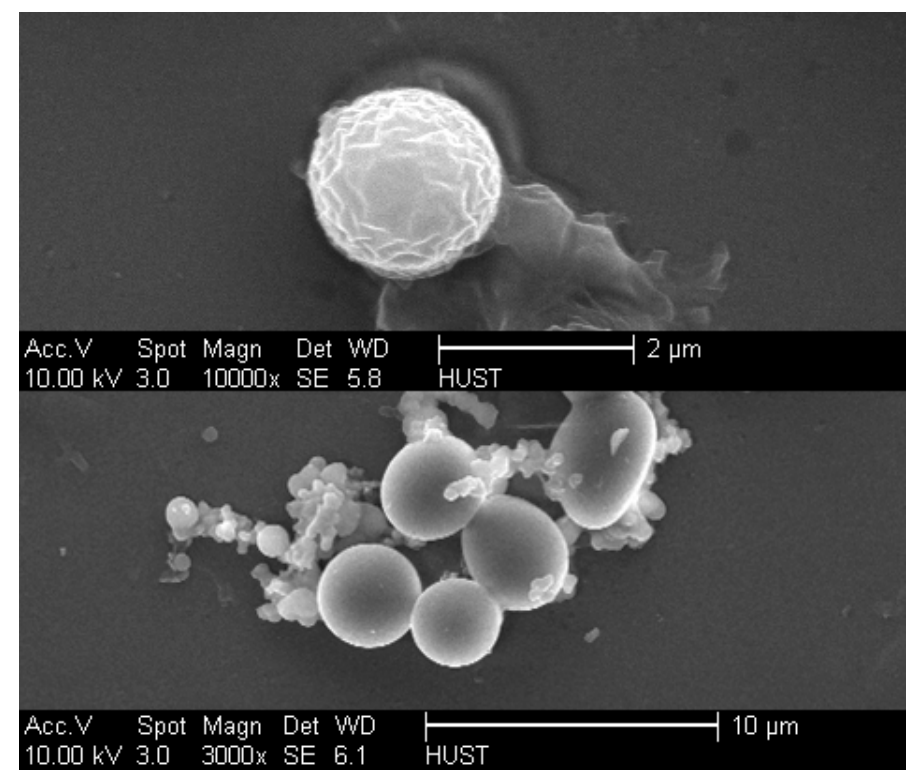

Figure 1. SEM images of the synthesized particles.

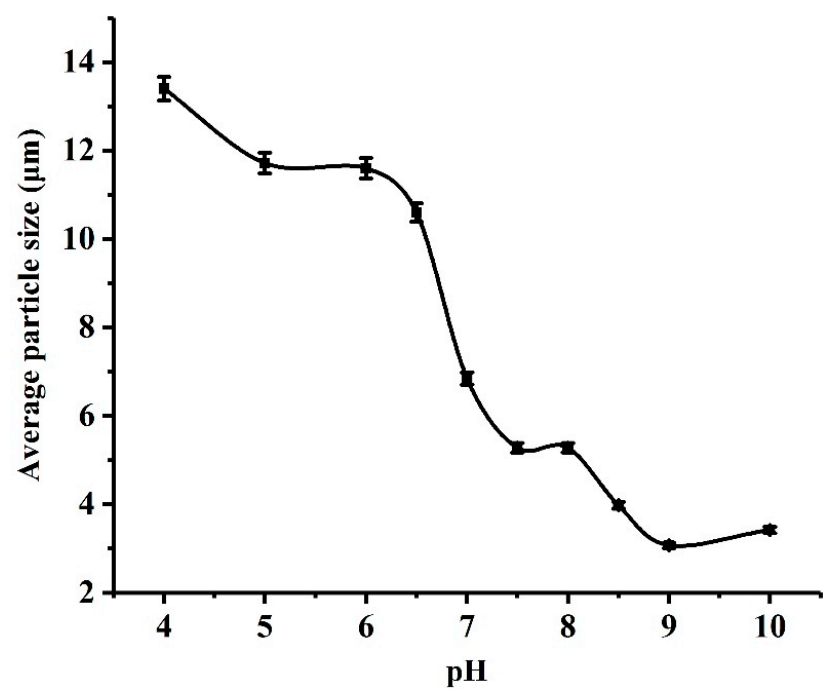

Figure 2. Average particle sizes variation of the synthesized matrix in different solution $\mathrm{pH}$ values.

\subsection{Lipase Immobilization and Characterization}

The immobilized BCL as a catalyst was achieved via physical absorption on the synthesized matrix. The effect of enzyme amount is presented in Figure 3. The ratios between lipase and matrix were ranged from 0.5 to 4.0 and a highest resolution activity was obtained at 2.0. Immobilization 
efficiency remained nearly $80 \%$ in the ratios from 2.0 to 4.0 . To minimize cost of the immobilized lipase preparation, the ratio of 2.0 (lipase: matrix) was chosen for later experiments.

Owing to the $\mathrm{pH}$ sensitivity of the carriers, the immobilization efficiency was significantly enhanced by changing the $\mathrm{pH}$ value during immobilization, thus, the effect of $\mathrm{pH}$ on immobilization was investigated (Figure 4). As described in "Section 2.1", lipase was immobilized along with the particle self-assembling through both embedding and adsorption, so the immobilization efficiency was increased with the increment of particle sizes and the highest immobilization efficiency was achieved at $\mathrm{pH}$ 4.0. Immobilization $\mathrm{pH}$ was not only related to the immobilization efficiency but also to the lipase activity. As the 'pH memory' theory [18] described, when enzymes were immobilized from an aqueous phase, they maintained the ionization, so they could preserve the catalytic activity after immobilization. Meanwhile, it can be seen from Figure 4 that the activity reached its maximum at pH 6.5 but reduced obviously under an acidic environment, even the immobilization efficiency was higher. Thus, the immobilized lipase as catalyst in resolution reaction should be prepared in a nearly neutral buffer with $\mathrm{pH} 6.5$, where the particle size changed greatly.

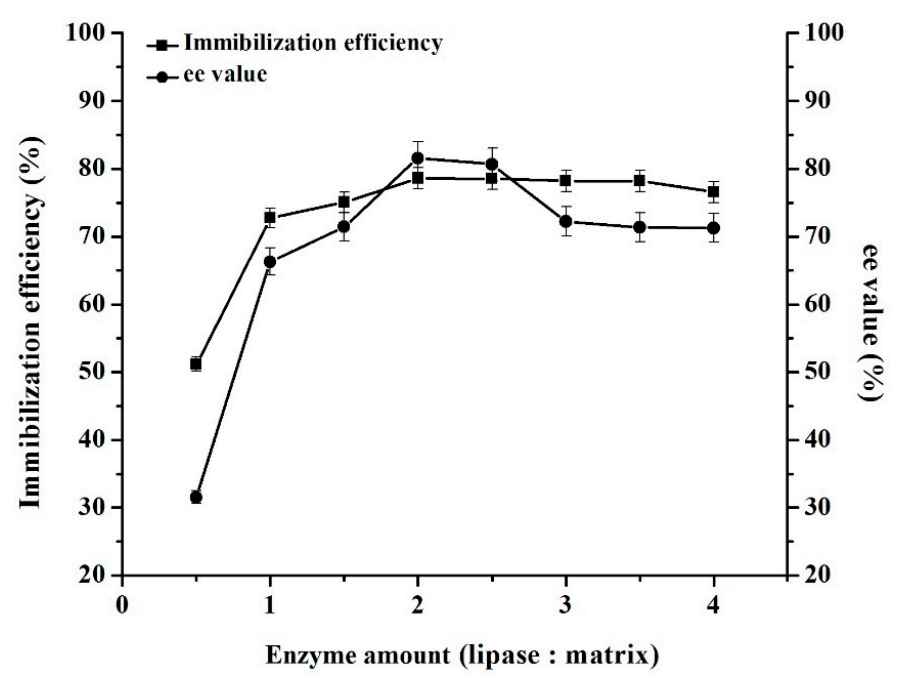

Figure 3. Effects of enzyme amount (lipase: matrix) on the immobilization efficiency and ee value in the solution $\mathrm{pH}$ of 7 . (Reaction conditions: $0.02 \mathrm{~g}$ immobilized lipase as catalyst, $45^{\circ} \mathrm{C}, 1 \mathrm{~h}$ ).

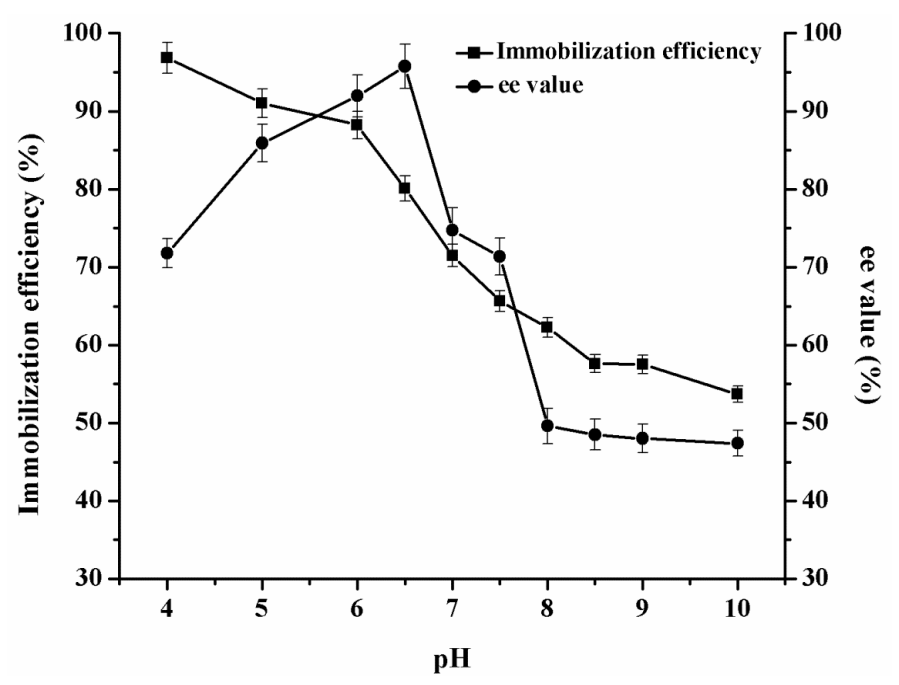

Figure 4. Effects of solution $\mathrm{pH}$ values (4-10) on the immobilization efficiency and ee value with enzyme amount ratio of 2.0. (Reaction conditions: $0.02 \mathrm{~g}$ immobilized lipase as catalyst, $45^{\circ} \mathrm{C}, 1 \mathrm{~h}$ ). 
In addition, the immobilized BCL was visualized by a confocal laser scanning microscopy (CLSM) [24]. As can be seen from Figure 5, the synthesized carrier displayed as grey component in the vision, and FITC (fluorescein iso-thiocyanate) labeled BCL delivered a green signal under the microscopy, providing a direct evidence for successful immobilization of the lipase.

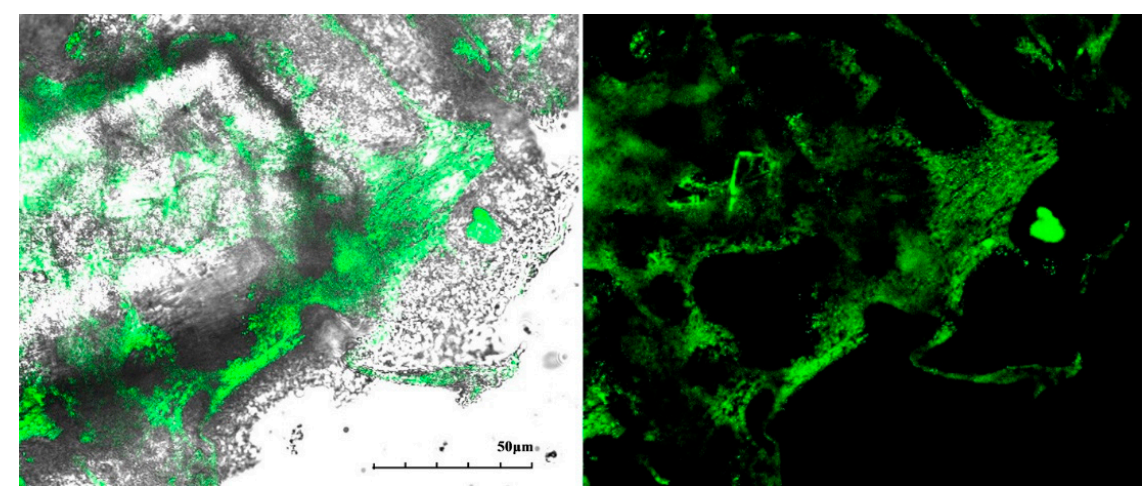

Figure 5. Confocal laser scanning microscopy (CLSM) images of the immobilized BCL labeled with FITC (showing a green signal).

\subsection{Catalytic Performance}

\subsubsection{Effect of Reaction Time}

The effect of reaction time on conversion and enantioselectivity $\left(e e_{s}\right)$ in the chiral resolution reaction of $(R, S)$-1-phenylethanol is presented in Figure 6. During the catalytic resolution, the conversion and $e e_{S}$ increased with the extension of reaction time and showed a consistent tendency. At the first $60 \mathrm{~min}$, the reaction had an extremely high reaction rate with the initial one at $79.41 \mu \mathrm{mol} / \mathrm{min} \cdot \mathrm{g}$, and at $90 \mathrm{~min}$ the conversion rate and $e e_{s}$ respectively attained nearly $50 \%$ and $90 \%$. After $180 \mathrm{~min}$, the conversion and $e e_{s}$ were roughly stabilized at a relatively high level, meaning the reaction reached its equilibrium. The conversion rate was nearly $50 \%$ and $e e_{S}$ was close to $100 \%$, indicating that BCL had high enantioselectivity for $(R)-1$-phenylethanol. Nevertheless, the free BCL exhibited very low activity, and only the Pullulan carrier as control didn't show any catalytic activity in this reaction. Additionally, our previous study [9] also proved that the immobilized BCL showed a significant higher initial reaction rate than the freeform.

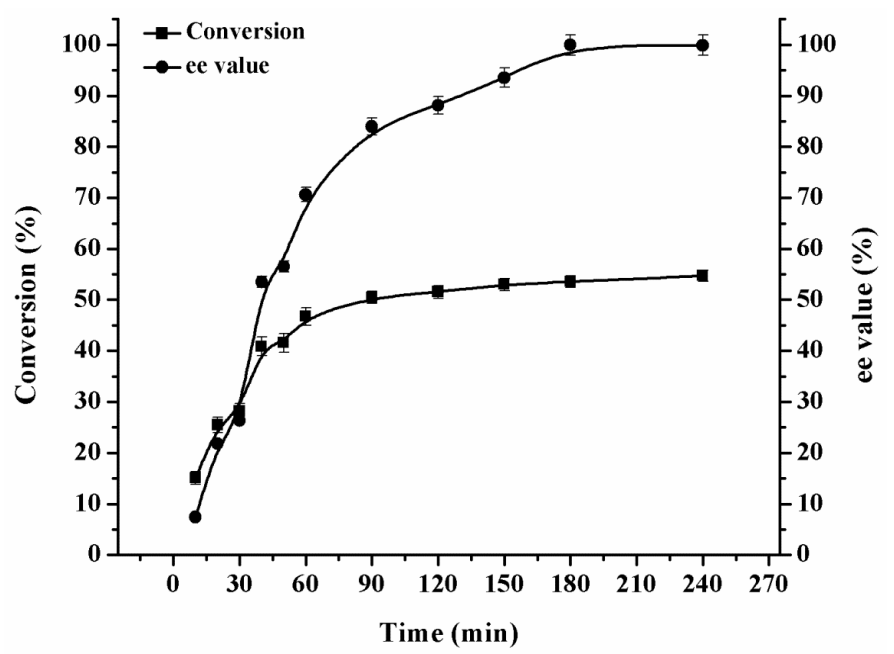

Figure 6. Time curve of resolution $(R, S)$-1-phenylethanol using $0.02 \mathrm{~g}$ immobilized BCL as catalyst in $45^{\circ} \mathrm{C}$. 


\subsubsection{Effect of Temperature}

The influence of reaction temperature was important to enzyme activity as a proper temperature may lead to the structure change of lipase active site, resulted in enzymatic activation. As shown in Figure 7, the immobilized BCL exhibited a relatively high catalytic activity when the temperature reached $35{ }^{\circ} \mathrm{C}$ and then gradually increased. Below $35{ }^{\circ} \mathrm{C}$, lipase protein structure might keep an inactive form owing to the close of the active site. With the increase of environment temperature, the structure was turned into an activated form and the substrates could easily get access to the active site, resulting in a greatly improved catalytic activity. The highest conversion (and $e e_{s}$ ) was achieved at $55{ }^{\circ} \mathrm{C}$, and then the activity decreased beyond this temperature, which probably was due to the inactivation of protein in elevated temperature. In the range of $35-65^{\circ} \mathrm{C}$, the catalytic efficiency kept relatively high where conversion rate was over $45 \%$ and $e e_{S}$ was more than $80 \%$, indicating that the immobilized BCL had a good thermo-stability. It is in good agreement with our previous work $[3,9,25]$.

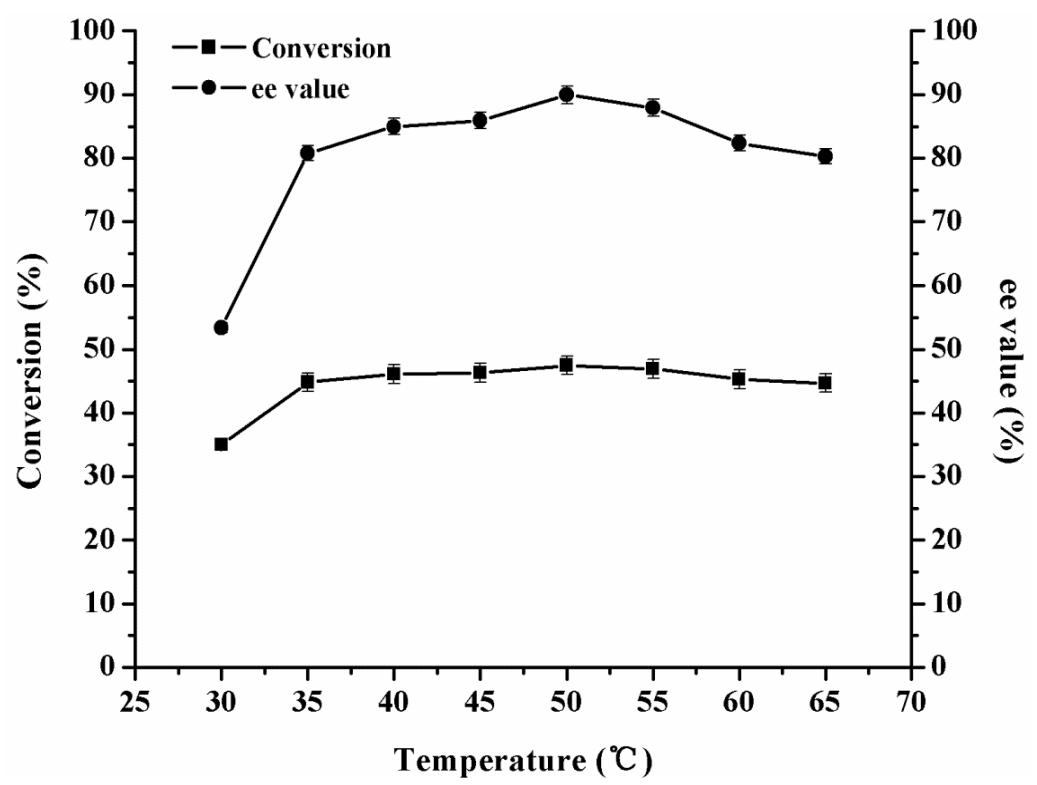

Figure 7. Temperature curve of resolution $(R, S)-1$-phenylethanol using $0.02 \mathrm{~g}$ immobilized BCL as catalyst for $1 \mathrm{~h}$.

\subsubsection{Catalytic Reusability and Storage Stability}

It is important for a catalyst to be reusable in industrial application as it can significantly reduce production cost. Thus, catalytic reusability of the immobilized BCL was further explored and is presented in Figure 8. It can be seen that centrifugation could easily separate the catalyst from the reaction system and was reused for 10 cycles. The activity slightly reduced in the first several cycles and then remained above $80 \%$ of its original activity, exhibiting very good operationability and reusability. Moreover, the immobilized BCL also presented fairly good storage stability. It could remain over $80 \%$ activity after storage for 20 days at room temperature in a drying environment (Figure 9). The above results demonstrated that the immobilized BCL is not only well applicable in research experiments but also possesses a promising prospect in large-scale industrial applications. 


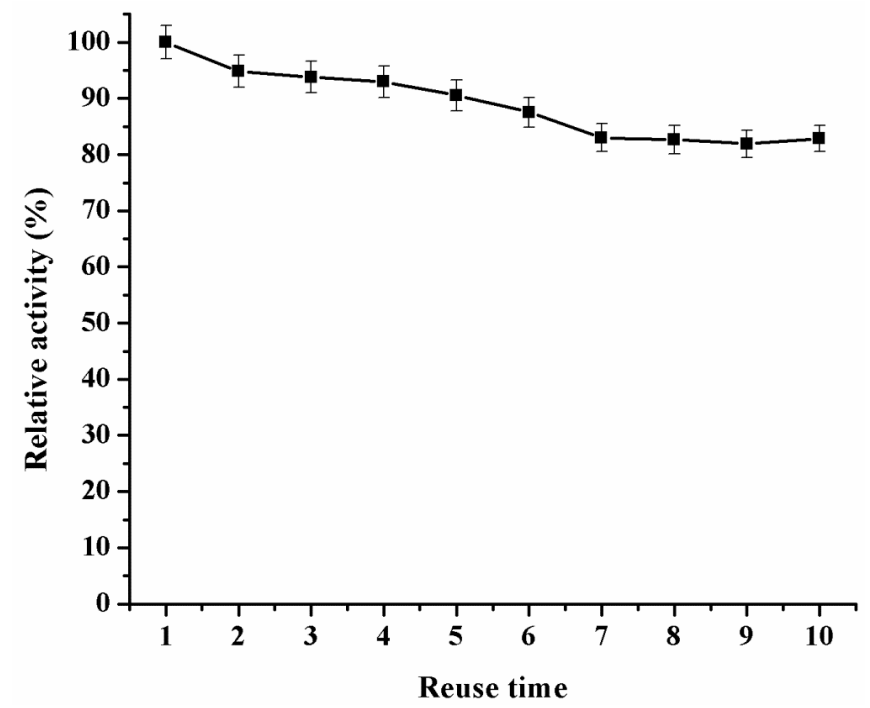

Figure 8. Reusability of immobilized lipase in resolution reaction. (Reaction conditions: $0.02 \mathrm{~g}$ immobilized BCL, $45^{\circ} \mathrm{C}, 1 \mathrm{~h}$ ).

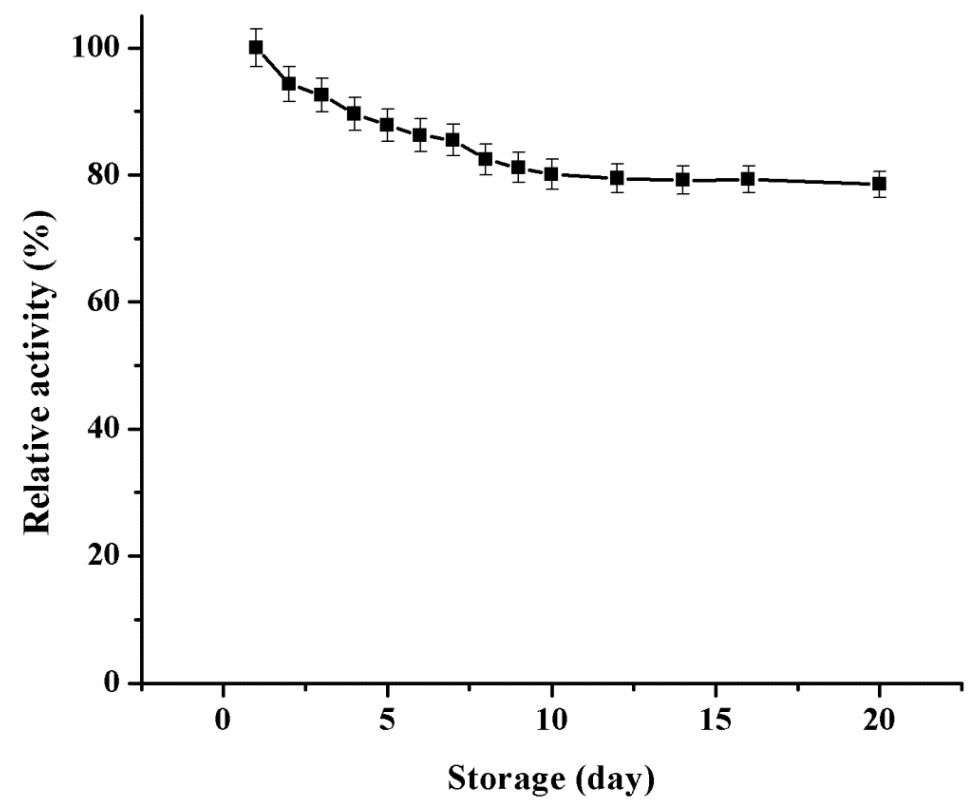

Figure 9. Storage stability of immobilized lipase in resolution reaction. (Reaction conditions: $0.02 \mathrm{~g}$ immobilized BCL, $45^{\circ} \mathrm{C}, 1 \mathrm{~h}$ ).

\subsection{In Comparison with Other Enzymes}

Pullulan has been widely employed in immunity therapy researches as a promising carrier of protein drug. However, there were few reports on immobilization of enzyme with pullulan since the patent "Enzyme Immobilized with Pullulan Gel" was published in 1981. In recent years, Swati and Rekha synthesized a kind of alginate beads made from pullulan-complexed $\alpha$-amylase and glucosidase via entrapment immobilization method [26]. The addition of pullulan obviously enhanced the immobilization efficiency and the beads of enzymes-pullulan complex showed higher enzyme activity in hydrolysis of starch than the corresponding beads of free enzymes. In this work, the resolution efficiency of BCL was largely improved by immobilizing it on the modified pullulan particles. Under the optimal reaction conditions, resolution equilibrium could be achieved within $2 \mathrm{~h}$ 
where conversion rate reached $50 \%$ and the corresponding $e e_{s}$ was $99.2 \%$. While in the same conditions, the free BCL needs $30 \mathrm{~h}$ to reach the reaction equilibrium.

It can be seen from Table 1, compared with related works on chiral resolution published in the past decades [9,27-32], the immobilized BCL in this work exhibited a higher enantioselectivity and a shorter reaction time $(2 \mathrm{~h})$. As BCL was immobilized through physical absorption, the enhancement of resolution efficiency was mainly attributable to the properties of $\mathrm{pH}$ sensitive particles. During the lipase immobilization, a proper $\mathrm{pH}$ value could lead to a sharply increase in particle size, which would provide even larger spherical surface for lipase immobilization, resulting in higher immobilization efficiency as well as easier access of substrates to the lipase. Moreover, the synthesized particles could be uniformly dispersed in the reaction system, and easily separated by centrifugation for the subsequent reuse. These results suggest that the modified pullulan is a suitable immobilization carrier and has a good potential for lipase immobilization in the future.

Table 1. Comparison of the enantioselectivity of other enzymes.

\begin{tabular}{cccccc}
\hline Lipase from & Immobilization Carrier & Conversion (\%) & $\boldsymbol{e e}_{\mathbf{s}} \mathbf{( \% )}$ & Time (h) & References \\
\hline C. rugosa & $\begin{array}{c}\text { Magnetic } \beta \text {-cyclodextrin } \\
\text { nanoparticles }\end{array}$ & 49.5 & 98.0 & 24 & 28 \\
\hline C. rugosa & Magnetic chitosan nanoparticles & 50.8 & 79.1 & 140 & 29 \\
\hline Candida sp. 99-125 & $\begin{array}{c}\text { Aminopropyl-grafted mesoporous } \\
\text { silica nanotubes }\end{array}$ & NM & 80.0 & 90 & 30 \\
\hline B. cepacia & Hybrid with calcium phosphate & 47.8 & 91.1 & 24 & 27 \\
\hline B. cepacia & Active carbon cloth & 46.0 & 32.0 & 24 & 31 \\
\hline B. cepacia & pH-responsive particles & 50.0 & 99.2 & 2 & This work \\
\hline B. cepacia & Free lipase & 50.0 & 99.0 & 30 & 9 \\
\hline P. cepacia & Free lipase & 7.1 & 7.7 & 48 & 32 \\
\hline
\end{tabular}

${ }^{*}$ NM: not measured in the report.

\section{Experimental}

\subsection{Materials}

Burkholderia cepacia lipase (BCL) powder was bought from Amano, Nagoya-shi, Aichi, Japan. Pullulan polysaccharide was obtained from Aladdin, Shanghai, China. $(R, S)$-1-phenylethanol was bought from Sigma Aldrich Co., Ltd., St. Louis, MO, USA. High-performance liquid chromatography (HPLC) grade organic solvents were purchased from TEDIA, Fairfield, OH, USA. Acetic anhydride, succinic anhydride, vinyl acetate, $n$-heptane and other reagents were bought from Sinopharm Chemical Reagent Co., Ltd., Shanghai, China.

\subsection{Synthesizing $p H$-Responsive Particles from Pullulan Polysaccharide}

As reported by Kun and You [33], pullulan polysaccharide was firstly modified by acetylation forming pullulan acetate (PA). Then, PA was succinylated and conjugated with sulfadimethoxine (SDM). Finally, the polymers were self-assembled into hydrogel particles using a diafiltration method, and then the pullulan derivative was obtained. Subsequently, the particles were filtered and dried in a thermostatic vacuum drier. The synthesized carrier turned into a kind of white precipitation and then it was ground into powder for later use.

\subsection{Particle Size and Specific Surface Area Measurement}

Dynamic light scattering (DLS) analysis was utilized to measure the average particle size of the resultant carrier. Before the DLS examination, particle samples were incubated in solution buffer with different $\mathrm{pH}$ for $12 \mathrm{~h}$. To investigate the effect of $\mathrm{pH}$ on particle size, three different kinds of solution buffers were used. They were $\mathrm{Na}_{2} \mathrm{HPO}_{4}$-citrate acid buffer $(0.2 \mathrm{M}, \mathrm{pH}$ 4.0-5.0), sodium phosphate buffer (0.2 M, pH 6.0-8.0), and Tris- $\mathrm{HCl}$ buffer (0.2 M, pH 9.0-10.0). In addition, 
the specific surface areas of the synthesized particles were also performed and calculated using BET (Brunauer-Emmett-Teller) method in $\mathrm{N}_{2}$ adsorption [34].

\subsection{Lipase Immobilization}

The synthesized particles were used as the immobilization carrier. A proper quantity of lipase was dissolved in $5 \mathrm{~mL}$ buffer solution containing $0.1 \mathrm{~g}$ immobilization carrier in a $50 \mathrm{~mL}$ tube. The mixture was incubated with rotary shaking under $37^{\circ} \mathrm{C}$ at $7.2 \mathrm{~g}$ for $12 \mathrm{~h}$. The supernatant were removed by centrifugation at $4{ }^{\circ} \mathrm{C}, 25,800 \mathrm{~g}$ for $10 \mathrm{~min}$. The frozen vacuum drier was used to dehydrate the immobilized lipase and then it was ground into powder for later use. During this procedure, the effect of lipase amount on immobilization efficiency was examined and optimized. The protein content of the supernatant was mensurated via the Bradford's method using bovine serum albumin (BSA) as standard [35]. Immobilization efficiency (\%) was estimated via Equation (1).

$$
\text { Immobilization efficiency }(\%)=\frac{\text { immobilized protein }}{\text { total loading protein }} \times 100 \%
$$

\subsection{Catalyzing Resolution of ( $R, S)$-1-Phenylethanol and Efficiency Evaluation}

$1 \mathrm{mmol}$ racemic 1-phenylethanol, $4 \mathrm{mmol}$ vinyl acetate and $5 \mathrm{~mL}$ pure heptane were mixed together to start the reactions (Scheme 1). The mixture and $0.02 \mathrm{~g}$ immobilized or free BCL as catalysts were added into a $50 \mathrm{~mL}$ stoppered flask, shaking at $45^{\circ} \mathrm{C}, 7.2 \mathrm{~g}$ for $60 \mathrm{~min}$. Meanwhile, only the Pullulan carrier without the enzyme was also used in this reaction as a control. During the catalyzing process, the effects of reaction time, temperature and $\mathrm{pH}$ on resolution efficiency and the performances of reuse and storage were totally examined. After the reactions, the catalysts were removed by centrifugation at $4{ }^{\circ} \mathrm{C}, 25,800 \mathrm{~g}$ for $2 \mathrm{~min}$. A $0.45 \mu \mathrm{m}$ filter was used to filter the samples and HPLC was used to analyze all the samples. The resolution reaction mentioned above was utilized to measure the enzyme activity. One unit (U) of enzyme activity was defined as the amount of enzyme that produces $1 \mu \mathrm{mol} \alpha$-phenylethyl acetate in one minute under the assay conditions. According to our previous work [36], substrate and product were analyzed by HPLC (Model 2300-525, Scientific Systems, Inc. (SSI), State College, PA, USA) with a Chiral OD-H column $(4.6 \mathrm{~mm} \times 250 \mathrm{~mm}$, Daicel Chemical, Tokyo, Japan). The mobile phase was composed of hexane/2-propanol alcohol at 95/5 $(v / v)$ and the flow rate was $1.0 \mathrm{~mL} \cdot \mathrm{min}^{-1}$. The samples were detected at $254 \mathrm{~nm}$ (Model $525 \mathrm{UV}$ Detector, Scientific Systems, Inc. (SSI), State College, PA, USA). In the above condition, (R)- and (S)-1-phenylethanol were separated and appeared in different resulted peaks of HPLC between 7 and $10 \mathrm{~min}$. The same conditions were used to run all the samples as stated above.

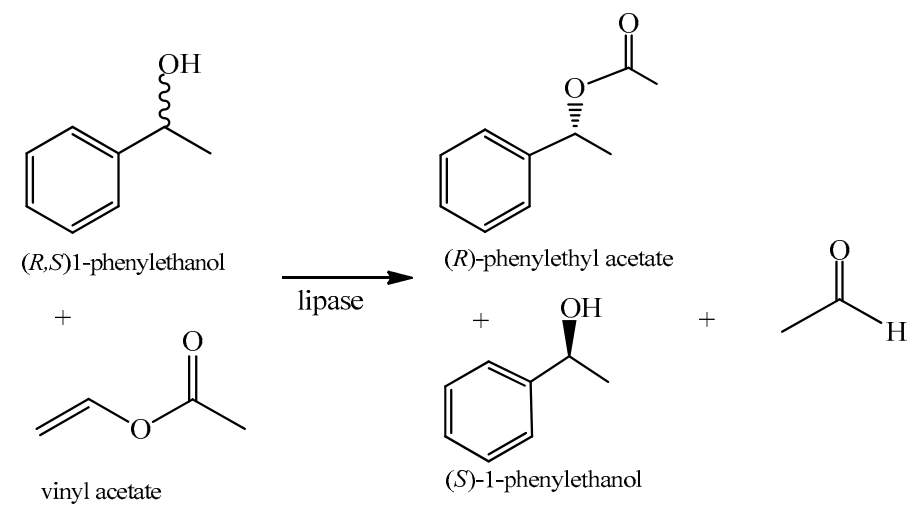

Scheme 1. Lipase catalyzed resolution of $(R, S)$-1-phenylethanol. 
As Chen et al. [37] described, enantioselectivity was represented by $E$ value and it was calculated by Equation (2); substrate enantiomeric excess $\left(e e_{s}\right)$ was estimated by Equation (3), and substrate conversion (C) computed by Equation (4).

$$
\begin{gathered}
E=\frac{\ln \left[(1-C)\left(1-e e_{s}\right)\right]}{\ln \left[(1-C)\left(1+e e_{s}\right)\right]} \\
e e_{S}=\frac{S-R}{S+R} \\
C=\frac{S_{0}+R_{0}-(S+R)}{S_{0}+R_{0}}
\end{gathered}
$$

where, $S_{0}$ and $R_{0}$ respectively represent the concentrations of the (S)- and (R)- enantiomers of 1-phenylethanol before the reaction; $S$ and $R$ represent the concentrations of the $(S)$ - and $(R)$ enantiomers of 1-phenylethanol after the reaction.

\subsection{Characterization via SEM and CLSM for the Probable Mechanism for $p H$ Sensitivity}

Morphology characterization of the synthesized particles was analyzed by scanning electron microscope (Nova Nano SEM 450, FEI Company, and Eindhoven, The Netherlands). The samples were coated with gold using a sputter coating system and tested under an acceleration voltage of $5 \mathrm{kV}$.

The immobilized lipase on the synthesized particles was examined through a confocal laser scanning microscopy (CLSM) with a SIM scanner (Olympus FV1000 Co., Tokyo, Japan) to test the fluorescencent signal from the FITC (fluorescein iso-thiocyanate)-marked immobilized BCL. The labeling procedure was as follows [38]: Firstly, lipase was dissolved in sodium phosphate buffer solution ( $\mathrm{pH} 7.0,0.05 \mathrm{M}$ ) with a final concentration at $10 \mathrm{mg} \cdot \mathrm{mL}^{-1}$ and fluorescein iso-thiocyanate diffused in dimethyl sulfoxide (DMSO) and the final concentration was $1 \mathrm{mg} \cdot \mathrm{mL}^{-1}$. Secondly, the mixture of lipase solution $(5 \mathrm{~mL})$ together with FITC $(100 \mu \mathrm{L})$ was incubated at $4{ }^{\circ} \mathrm{C}$ without light for $24 \mathrm{~h}$. Lastly, the residual FITC was separated from the mixture by dialyzing with double distilled water and the immobilized lipase labeled with FITC was achieved.

\section{Conclusions}

In this study, a new particle was synthesized using diafiltration method from the modified pullulan polysaccharide. The size of the derivative particle exhibited $\mathrm{pH}$ sensitivity and increased along with the decrease of solution $\mathrm{pH}$, rendering itself a series of unique merits in enzyme immobilization. $\mathrm{BCL}$, a promising biocatalyst in transesterification reaction, was immobilized on the synthesized particle and employed in $(R, S)$-1-phenylethanol chiral resolution. The highest enantioselectivity was achieved at $\mathrm{pH} 6.5$ because the particle size was obviously increased, leading to a larger specific surface area and resulting in easier access of substrates to active site of the immobilized lipase. The immobilized BCL also exhibited very good operation stability; after 10 reuse cycles, about $80 \%$ original activity still remained, and over $80 \%$ relative activity remained after storage for 20 days at room temperature in a drying environment. More importantly, it could sharply shorten the reaction time to $2 \mathrm{~h}$ with a conversion rate of $50.0 \%$ and $e e_{s}$ at $99.2 \%$, much better than the ones reported in the literature. This study indicates that the immobilized BCL exhibits good catalysis performance and possesses a prosperous prospect in future industrial application.

Acknowledgments: This work is financially supported by the National Natural Science Foundation of China (grant Nos. 31070089, 31170078 and J1103514), the National High Technology Research and Development Program of China (grant Nos. 2013AA065805 and 2014AA093510), the National Natural Science Foundation of Hubei Province (grant No. 2015CFA085), and the Fundamental Research Funds for HUST (grant Nos. 2014NY007, 2017KFYXJJ212, 2017KFXKJC010, 2017KFTSZZ001). Many thanks are indebted to the Analytical and Testing Center of Huazhong University of Science and Technology for their valuable assistances in the FTIR, TEM, and XRD measurements. 
Author Contributions: Li Xu and Yunjun Yan conceived and designed the experiments; Caixia Ke and Guli Cui performed the experiments; Guli Cui analyzed the data and wrote the paper; Yanli Fan assisted in part of the experiments; Guli Cui, Li Xu and Yunjun Yan contributed to the revision and proofreading of the manuscript.

Conflicts of Interest: The authors declare no conflict of interest.

\section{References}

1. Singh, A.K.; Mukhopadhyay, M. Overview of Fungal Lipase: A Review. Appl. Biochem. Biotechnol. 2012, 166, 486-520. [CrossRef] [PubMed]

2. Jaeger, K.E.; Eggert, T. Lipases for biotechnology. Curr. Opin. Biotechnol. 2002, 13, 390-397. [CrossRef]

3. Liu, T.; Liu, Y.; Wang, X.; Li, Q.; Wang, J.; Yan, Y. Improving catalytic performance of Burkholderia cepacia lipase immobilized on macroporous resin NKA. J. Mol. Catal. B Enzym. 2011, 71, 45-50. [CrossRef]

4. Pan, S.; Xue, L.; Xie, Y.; Yi, Y.; Chong, L.; Yan, Y.; Yun, L. Esterification activity and conformation studies of Burkholderia cepacia lipase in conventional organic solvents, ionic liquids and their co-solvent mixture media. Bioresour. Technol. 2010, 101, 9822-9824. [CrossRef] [PubMed]

5. Yang, J.; Guo, D.; Yan, Y. Cloning, expression and characterization of a novel thermal stable and short-chain alcohol tolerant lipase from Burkholderia cepacia strain G63. J. Mol. Catal. B Enzym. 2007, 45, 91-96. [CrossRef]

6. Drauz, K.; Waldmann, H. Enzyme Catalysis in Organic Synthesis: A Comprehensive Handbook; Wiley-VCH: Hoboken, NJ, USA, 2002; pp. 991-1033.

7. Ghanem, A.; Aboul-Enein, H.Y. Lipase-Mediated Chiral Resolution of Racemates in Organic Solvents. Cheminform 2004, 15, 3331-3351. [CrossRef]

8. Wang, J.; Ma, C.; Bao, Y.; Xu, P. Lipase entrapment in protamine-induced bio-zirconia particles: Characterization and application to the resolution of $(R, S)-1$-phenylethanol. Enzyme Microb. Technol. 2012, 51, 40-46. [CrossRef] [PubMed]

9. Li, X.; Huang, S.; Xu, L.; Yan, Y. Improving activity and enantioselectivity of lipase via immobilization on macroporous resin for resolution of racemic 1-phenylethanol in non-aqueous medium. BMC Biotechnol. 2013, 13, 92. [CrossRef] [PubMed]

10. Sang, H.L.; Doan, T.; Won, K.; Ha, S.H.; Koo, Y.M. Immobilization of lipase within carbon nanotube-silica composites for non-aqueous reaction systems. J. Mol. Catal. B Enzym. 2010, 62, 169-172. [CrossRef]

11. Jesionowski, T.; Zdarta, J.; Krajewska, B. Enzyme immobilization by adsorption: A review. Adsorption 2014, 20, 801-821. [CrossRef]

12. Homaei, A.A.; Sariri, R.; Vianello, F.; Stevanato, R. Enzyme immobilization: An update. J. Chem. Biol. 2013, 6, 185-205. [CrossRef] [PubMed]

13. Prajapati, V.D.; Jani, G.K.; Khanda, S.M. Pullulan: An exopolysaccharide and its various applications. Carbohydr. Polym. 2013, 95, 540-549. [CrossRef] [PubMed]

14. Singh, R.S.; Kaur, N.; Kennedy, J.F. Pullulan and pullulan derivatives as promising biomolecules for drug and gene targeting. Carbohydr. Polym. 2015, 123, 190-207. [CrossRef] [PubMed]

15. Fundueanu, G.; Constantin, M.; Ascenzi, P. Preparation and characterization of $\mathrm{pH}$ - and temperaturesensitive pullulan microspheres for controlled release of drugs. Biomaterials 2008, 29, 2767-2775. [CrossRef] [PubMed]

16. Hirakura, T.; Yasugi, K.; Nemoto, T.; Sato, M.; Shimoboji, T.; Aso, Y.; Morimoto, N.; Akiyoshi, K. Hybrid hyaluronan hydrogel encapsulating nanogel as a protein nanocarrier: New system for sustained delivery of protein with a chaperone-like function. J. Control. Release 2010, 142, 483-489. [CrossRef] [PubMed]

17. Li, H.; Bian, S.; Huang, Y.; Liang, J.; Fan, Y.; Zhang, X. High drug loading pH-sensitive pullulan-DOX conjugate nanoparticles for hepatic targeting. J. Biomed. Mater. Res. A 2014, 102, 150-159. [CrossRef] [PubMed]

18. Costantino, H.R.; Griebenow, K.; Langer, R.; Klibanov, A.M. On the pH memory of lyophilized compounds containing protein functional groups. Biotechnol. Bioeng. 1997, 53, 345-348. [CrossRef]

19. Hirohara, H.; Nabeshima, S.; Fujimoto, M.; Nagase, T. Enzyme Immobilization with Pullulan Gel. U.S. Patent 4247642, 27 January 1981.

20. Chua, L.S.; Sarmidi, M.R. Immobilised lipase-catalysed resolution of $(R, S)$-1-phenylethanol in recirculated packed bed reactor. J. Mol. Catal. B Enzym. 2004, 28, 111-119. [CrossRef] 
21. Cui, C.; Xie, R.; Tao, Y.; Zeng, Q.; Chen, B. Improving performance of Yarrowia lipolytica lipase lip2-catalyzed kinetic resolution of $(R, S)$-1-phenylethanol by solvent engineering. Biocatal. Biotransform. 2015, 33, 38-43. [CrossRef]

22. Ríos, A.P.D.L.; Rantwijk, F.V.; Sheldon, R.A. Effective resolution of 1-phenyl ethanol by Candida antarctica lipase B catalysed acylation with vinyl acetate in protic ionic liquids (PILs). Green Chem. 2012, 14, 1584-1588. [CrossRef]

23. Park, S.Y.; Bae, Y.H. Novel pH-sensitive polymers containing sulfonamide groups. Macromol. Rapid Commun. 1999, 20, 269-273. [CrossRef]

24. Paddock, S.W. Confocal laser scanning microscopy. Biotechniques 1999, 27, 992-1004. [PubMed]

25. Ke, C.; Li, X.; Huang, S.; Xu, L.; Yan, Y. Enhancing enzyme activity and enantioselectivity of Burkholderia cepacia lipase via immobilization on modified multi-walled carbon nanotubes. RSC Adv. 2014, 4, 57810-57818. [CrossRef]

26. Jadhav, S.B.; Singhal, R.S. Pullulan-complexed $\alpha$-amylase and glucosidase in alginate beads: Enhanced entrapment and stability. Carbohydr. Polym. 2014, 105, 49-56. [CrossRef] [PubMed]

27. Ke, C.; Fan, Y.; Chen, Y.; Xu, L.; Yan, Y. A new lipase-inorganic hybrid nanoflower with enhanced enzyme activity. RSC Adv. 2016, 6, 19413-19416. [CrossRef]

28. Ozyilmaz, E.; Sayin, S.; Arslan, M.; Yilmaz, M. Improving catalytic hydrolysis reaction efficiency of sol-gel-encapsulated Candida rugosa lipase with magnetic $\beta$-cyclodextrin nanoparticles. Colloids Surf. B 2014, 182-189. [CrossRef] [PubMed]

29. Siódmiak, T.; Ziegler-Borowska, M.; Marszałł, M.P. Lipase-immobilized magnetic chitosan nanoparticles for kinetic resolution of ( $R, S)$-ibuprofen. J. Mol. Catal. B Enzym. 2013, 94, 7-14. [CrossRef]

30. Bai, W.; Yang, Y.; Tao, X.; Chen, J.; Tan, T. Immobilization of lipase on aminopropyl-grafted mesoporous silica nanotubes for the resolution of $(R, S)-1$-phenylethanol. J. Mol. Catal. B Enzym. 2012, 76, 82-88. [CrossRef]

31. Hara, P.; Mikkola, J.; Murzin, D.Y.; Kanerva, L.T. Supported ionic liquids in Burkholderia cepacia lipase-catalyzed asymmetric acylation. J. Mol. Catal. B Enzym. 2010, 67, 129-134. [CrossRef]

32. Xue, P.; Yan, X.H.; Wang, Z. Lipase immobilized on HOOC-MCF: A highly enantioselective catalyst for transesterification resolution of $(R, S)$-1-phenylethanol. Chin. Chem. Lett. 2007, 18, 929-932. [CrossRef]

33. Na, K.; You, H.B. Self-assembled hydrogel nanoparticles responsive to tumor extracellular $\mathrm{pH}$ from pullulan derivative/sulfonamide conjugate: Characterization, aggregation, and adriamycin release in vitro. Pharm. Res. 2002, 19, 681-688. [CrossRef] [PubMed]

34. Park, E.Y.; Sato, M.; Kojima, S. Fatty acid methyl ester production using lipase-immobilizing silica particles with different particle sizes and different specific surface areas. Enzyme Microb. Technol. 2006, 39, 889-896. [CrossRef]

35. Kruger, N.J. The Bradford method for protein quantitation. In Methods in Molecular Biology; Walker, J.M., Ed.; Humana Press: London, UK, 1994; Volume 32, pp. 9-15.

36. Li, X.; Xu, L.; Wang, G.; Zhang, H.; Yan, Y. Conformation studies on Burkholderia cenocepacia lipase via resolution of racemic 1-phenylethanol in non-aqueous medium and its process optimization. Process Biochem. 2013, 48, 1905-1913. [CrossRef]

37. Chen, C.S.; Fujimoto, Y.; Girdaukas, G.; Sih, C.J. Quantitative analyses of biochemical kinetic resolutions of enantiomers. J. Am. Chem. Soc. 1982, 104, 7294-7299. [CrossRef]

38. Feng, S.; Li, G.; Fan, Y.; Yan, Y. Enhanced performance of lipase via microcapsulation and its application in biodiesel preparation. Sci. Rep. 2016, 6, 29670. [CrossRef]

(C) 2018 by the authors. Licensee MDPI, Basel, Switzerland. This article is an open access article distributed under the terms and conditions of the Creative Commons Attribution (CC BY) license (http://creativecommons.org/licenses/by/4.0/). 